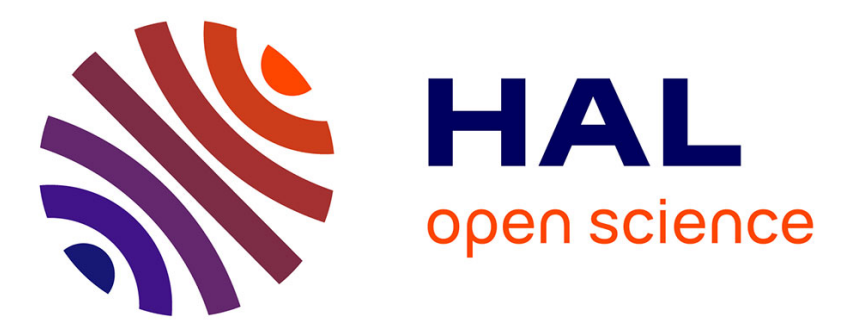

\title{
Influence of the crystallographic parameters of the grain boundary/grains system on the intergranular precipitation of austenite in a ferritic iron-nickel alloy
}

\author{
N. Benfetima, L. Priester
}

\section{- To cite this version:}

N. Benfetima, L. Priester. Influence of the crystallographic parameters of the grain boundary/grains system on the intergranular precipitation of austenite in a ferritic iron-nickel alloy. Revue de Physique Appliquée, 1986, 21 (2), pp.109-120. 10.1051/rphysap:01986002102010900 . jpa-00245416

HAL Id: jpa-00245416

https://hal.science/jpa-00245416

Submitted on 1 Jan 1986

HAL is a multi-disciplinary open access archive for the deposit and dissemination of scientific research documents, whether they are published or not. The documents may come from teaching and research institutions in France or abroad, or from public or private research centers.
L'archive ouverte pluridisciplinaire HAL, est destinée au dépôt et à la diffusion de documents scientifiques de niveau recherche, publiés ou non, émanant des établissements d'enseignement et de recherche français ou étrangers, des laboratoires publics ou privés. 
Classification

Physics Abstracts

$61.70 \mathrm{~N}-61.16 \mathrm{D}-64.70 \mathrm{~K}-64.75-68.48$

\title{
Influence of the crystallographic parameters of the grain boundary/grains system on the intergranular precipitation of austenite in a ferritic iron-nickel alloy
}

\author{
N. Benfetima and L. Priester \\ Laboratoire de Métallurgie Physique, Bât. 413, Université Paris XI, 91405 Orsay, France
}

(Reçu le 10 mars 1985, révisé le 22 octobre, accepté le 25 octobre 1985)

\begin{abstract}
Résumé. - L'objet des recherches présentées dans cet article est d'analyser les paramètres cristallographiques qui interviennent dans la formation au chauffage de l'austénite aux joints de grains de ferrite dans un alliage $\mathrm{Fe}-4 \%$ Ni. Dans les polycristaux, contrairement aux bicristaux, la structure d'équilibre du joint de grains de la phase mère ne semble pas jouer un grand rôle; cette constatation est probablement due aux faibles différences d'énergies entre les joints « au hasard » qui de plus contiennent des impuretés ségrégées. En revanche, les dislocations extrinsèques qui sont les principaux défauts de la structure intergranulaire constituent des sites de germination préférentielle. La morphologie et la croissance des précipités sont fortement influencées par la désorientation, dans chaque grain de ferrite, entre le plan du joint et l'interface ferrite-austénite de faible énergie la plus proche. L'observation des cristaux uniques de ferrite massive, formés lors du refroidissement de l'austénite, développés de part et d'autre du joint, est interprétée à partir de l'existence de relations particulières entre les deux grains de la ferrite-mère. Enfin, un effort est tenté pour classer les différentes morphologies des précipités intergranulaires cohérents ou partiellement cohérents en fonction de la cristallographie du système complexe « joint de grains/ grains/précipité ».
\end{abstract}

\begin{abstract}
The object of the research described in the present paper was to analyse the crystallographic parameters which may influence the formation on heating of austenite at ferrite grain boundaries in a $\mathrm{Fe}-4 \% \mathrm{Ni}$ alloy. In polycrystals, as opposed to bicrystals, the influence of the equilibrium structure of grain boundaries of the parent phase seems to be negligible; this can be attributed to the relatively close energies of the random and moreover impure boundaries. On the other hand, extrinsic dislocations, which are the main non-equilibrium components of the intergranular structure, act as preferential nucleation sites. The morphology and the growth of the precipitates were strongly influenced by the misorientation between the ferrite grain boundary plane and the nearest possible low-energy ferrite-austenite interface in each grain. The observation of apparently single crystals of massive ferrite, which derived by cooling from austenite and developed on both sides of some grain boundaries was interpreted by a particular orientation relationship between the two original adjoining grains. Finally an attempt of a morphological classification of the intergranular coherent or partially coherent precipitates was made on the basis of the complex crystallographic « grain-boundary/grains/precipitate » system.
\end{abstract}

\section{Introduction.}

The occurrence of precipitation at grain boundaries does affect most of the properties of polycrystalline materials as recrystallization, corrosion and mechanical properties. A good understanding of this phenomenon implies to take into account several characteristics of the intergranular new phase :

- its nature : intermetallic compound or primary equilibrium phase, metastable or stable phase;

- its distribution which can be homogeneous as a film between two grains or heterogeneous taking the form of crystals with various sizes along the same boundary; moreover this distribution strongly differs from one grain boundary to another one;

- its morphology : allotriomorphs with or without facet, sideplates, needles...

- its orientation relationship with the matrix, especially in the case of a coherent or a semi-coherent precipitate.

For a theoretical approach of the intergranular precipitation, the reader can refer to the following papers [1-5].

Most of the previous experimental studies concerning intermetallic compounds point out the influence 
of two sets of parameters on the intergranular precipitation [6-13] :

- The first one deals with the grain boundary itself : its misorientation, its plane, its defects,

- the second set emphasizes the position of the grain boundary plane relative to the close-packed planes or to the usual habit planes of the precipitates.

The respective importance of the different parameters is not well established. In particular, the efficiency of extrinsic dislocations as boundary nucleation sites is still controversial [14-21].

A few studies exist on the appearance of a primary solid solution at grain boundaries, with previously determined crystallographic parameters. In the case of ferrous alloys, the previous attempts concerned the precipitation on cooling of ferrite particles at austenite grain boundaries [22-23] but there are no data on the crystallography of the transformation on heating. It is the purpose of this work to study the early stages of the transformation $\alpha \rightarrow \gamma$ which occurs at grain boundaries in a iron $-4 \%$ nickel alloy. The choice of this alloy rests on the following reasons :

- The austenite appears at relatively low temperature $\left(640^{\circ} \mathrm{C}\right)$ which involves two important favourable consequences for the study. First, the diffusion coefficient of nickel in the alloy is small enough to avoid an extension of the $\gamma$-phase; this condition is necessary to go back to the nucleation of precipitates. Secondly, at temperatures just above $640^{\circ} \mathrm{C}$, it is highly likely that extrinsic dislocations are still present in grain boundaries as their accommodation processes are thermally activated ones $[20,21,24,25]$.

- It is possible to analyse at room temperature the orientation relationship established, at the temperature of the isothermal treatment, between the $\gamma$-phase and the ferrite $\alpha$. As a matter of fact, the $\gamma$ phase undergoes on cooling a "massive" transformation $\left(\gamma \rightarrow \alpha^{\prime}\right)$ without changes of composition; it is also well known that a N.W. (Nishiyama-Wassermann) or K-S (Kurdjumov-Sachs) relationship exists between the fcc $\alpha^{\prime}$ phase and the fcc $\gamma$-phase. Thus, at room temperature, the relationship between $\alpha$ and $\alpha^{\prime}$ allows us to go back to those between $\gamma$ and $\alpha$.

\section{Experimental.}

2.1 SPECIMENS. - All the present results were obtained from samples of high purity $\mathrm{Fe}-4 \% \mathrm{Ni}$ alloys containing about $150 \times 10^{-6}$ carbon. The alloys are austenitized for 24 hours at $1180^{\circ} \mathrm{C}$, then quenched to get a homogeneous distribution of carbon, then strongly cold-rolled. The isothermal transformation is performed either simultaneously to recrystallization at temperature between 645 and $675^{\circ} \mathrm{C}$ or after a $600^{\circ} \mathrm{C}$ recrystallization anneal which implies to extend the precipitation treatment at $735^{\circ} \mathrm{C}$.

Thin foils for Transmission Electron Microscopy (T.E.M.) were prepared from the sheet material by the double jet electrolytic polishing technique.
2.2 T.E.M. PROCEDURE. - The crystallographic parameters $(\theta|u v w|)$ of the $\alpha$-grain boundaries, with or without precipitate, were determined either by use of the stereographic projection or by calculation. A relative orientation between the two crystals was obtained with a limited precision of $2^{\circ}$ owing to the ferromagnetism of the samples. Then a normalization was achieved in order to obtain the standard misorientation [18-26].

Grain boundaries were classified into two groups according to their character « special » or " general ». Special boundaries include :

- low-angle boundaries,

- boundaries whose misorientation deviates slightly from an exact coincidence orientation relationship within $\Delta \theta$ given by Brandon's equation [27].

$$
\Delta \theta=\Delta \theta^{\circ} \Sigma^{-1 / 2}
$$

where $\Sigma$, the coincidence indice, is the ratio of the volume of the coincidence unit cell to that of the crystal unit cell. $\Delta \theta^{\circ}$ was chosen equal to $8^{\circ}[28]\left({ }^{1}\right)$; they were called "CSL " boundaries in the text;

- boundaries which preserve a repeat order only in one direction in the interface described by any rotation around a low indices direction $\langle 100\rangle$, $\langle 110\rangle$ or $\langle 111\rangle$; they were termed Coincident Axial Direction (CAD) boundaries [29].

In the region where an intergranular precipitation occurred the grain boundary planes and, if necessary, the directions of the extrinsic dislocations lines were determined with an accurary of $\pm 4^{\circ}$.

The orientation relationship between the $\alpha$ and $\alpha^{\prime}$ phases was obtained by diffraction pattern analysis. By Analytical Electron Microscopy (AEM) we got the composition of the new phase. The latter confirms indirectly the nickel enrichment of the $\gamma$ phase.

\section{Preliminary discussion of the analysis of the " crystallographic grain boundary/grains/precipitate " system.}

Before analysing the influence of the relative position of the grain boundary plane in the two grains, it was necessary to define a criterion which allowed us to distinguish between a favourable and an unfavourable crystallography of the « $\alpha$-grain boundary $/ \alpha$ - grains/ $\gamma$ - precipitate " system (referred $\mathrm{GB} / \alpha / \gamma$ in the following lines).

First we were concerned with the energies of the $\alpha / \gamma$ interfaces which are still not well known, in particular because a mismatch exists between the bcc/fcc lattices whatever the interphase boundary orientation. Some attempts were made to predict theoretically the interface structures corresponding to lowest energy [30]. The interface matching was

( $\left.{ }^{1}\right)$ In most studies $\Delta \theta^{\circ}=15^{\circ}$ : the choice of $\Delta \theta^{\circ}=8^{\circ}$, leads to a more restrictive criterion of speciality (see Ref. [28]). 
defined by a linear misfit and simultaneously by a coincident atoms density as calculated in the case of $\theta$ precipitates in a $\mathrm{Al} 4 \% \mathrm{Cu}$ matrix [31]; otherwise, the organization of the misfit dislocations in semi-coherent interfaces accounted for their relatively low energy [32].

The present approach to the $\mathrm{Fe}-\mathrm{Ni}$ system was established on the basis of the conclusions of these previous works. The main hypothesis was that a lowenergy interface is most probably constituted by a $\gamma$-plane parallel to a $\alpha$-plane according to the $\mathrm{N}-\mathrm{W}$ or K-S orientation relationship between the precipitate and the parent phase. For any one of these possible interfaces, linear misfit $\delta$ are calculated along two directions corresponding to two almost parallel atomic rows of the two lattices (Table I). Although we did not determine the coincident atoms density which could compensate a relatively high value of the misfit [31], it seems reasonable to think that the interface energies increase with the increasing linear misfits. Whatever the orientation relationship, KS or NW, the lowest energy interface must be :

$$
\{110\}_{\text {bcc }} / /\{111\}_{\text {fcc }} \text {. }
$$

In the present study all the information about the ferrite austenite orientation relationship must be derived from the observed $" \alpha$-ferrite $/ \alpha^{\prime}$-massive ferrite " ones. Taking into account the structure's heredity of the two phases $\alpha^{\prime}$ and $\gamma$, we assumed that a low energy $\alpha / \gamma$ interface created at high temperature involves on cooling the formation of a $\alpha / \gamma$ interface almot parallel to a $\{110\},\{001\},\{111\}$ or $\{211\}$ plane of the ferrite $\alpha$.

Otherwise it was pointed out, by theoretical and experimental studies $[6,8,10,11]$, that the intergranular precipitation is favoured by a low-angle $\phi$ between the grain-boundary plane and one of the low-energy interface. The value of $\phi$ must be less than a critical one, $\phi_{c}$, depending on the type of interface; $\phi_{\mathrm{c}}$ has a maximal value for the $\left[\{110\}_{\alpha} / /\{111\}_{\gamma}\right]$ interface.

Thus, it only remained to determine this angle $\phi$ between any grain-boundary plane containing precipitates and the nearest $\{110\},\{100\},\{111\}$ or $\{211\}$ plane in each grain of ferrite and to compare it to the critical value $\phi_{\mathrm{c}}$. In this study $\phi_{\mathrm{c}}$ was chosen equal to $8^{\circ}$ whatever the interface for the following reasons :

- This value corresponds to an austenite/ferrite orientation relationship within the maximum allowa-

Table I. - Linear misfits $\delta$ along two almost parallel directions of the two lattices in the different possible interfaces $\alpha / \gamma$.

\begin{tabular}{|c|c|c|c|}
\hline $\begin{array}{l}\text { Orientation } \\
\text { relationships }\end{array}$ & $\begin{array}{l}\text { Low-energy } \\
\text { interfaces }\end{array}$ & $\begin{array}{c}\text { Almost parallel directions } \\
\text { of the two lattices } \\
\mathrm{D}_{\mathrm{bcc}} / / \mathrm{D}_{\mathrm{fcc}} \\
\mathrm{D}_{\mathrm{bcc}} / / / \mathrm{D}_{\mathrm{fcc}}^{\prime}\end{array}$ & $\begin{array}{l}\text { Linear } \\
\text { misfits } \\
\delta\end{array}$ \\
\hline \multirow{6}{*}{$\begin{array}{l}\text { Nishiyama- } \\
\text { Wassermann }\end{array}$} & \multirow{2}{*}{$(\overline{1} 10)_{\mathrm{bcc}} / /(\overline{1} 11)_{\mathrm{fcc}}$} & {$[111]_{\mathrm{bcc}} / /[101]_{\mathrm{fcc}}$} & $+2 \%$ \\
\hline & & {$[\overline{11} 1]_{\mathrm{bcc}} / /[\overline{11} 0]_{\mathrm{fcc}}$} & $+2 \%$ \\
\hline & \multirow{2}{*}{$(001)_{\mathrm{bcc}} / /(0 \overline{1} 1)_{\mathrm{fcc}}$} & {$[110]_{\mathrm{bcc}} / /[211]_{\mathrm{fcc}}$} & $+7.6 \%$ \\
\hline & & {$[120]_{\mathrm{bcc}} / /[111]_{\mathrm{fcc}}$} & $-3.1 \%$ \\
\hline & \multirow{2}{*}{$(110)_{\mathrm{bcc}} / /(211)_{\mathrm{fcc}}$} & {$[1 \overline{1} 3]_{\mathrm{bcc}} / /[1 \overline{3} 1]_{\mathrm{fcc}}$} & $+25 \%$ \\
\hline & & {$[\overline{1} 13]_{\mathrm{bcc}} / /[\overline{11} 3]_{\mathrm{fcc}}$} & $+25 \%$ \\
\hline \multirow{6}{*}{$\begin{array}{l}\text { Kurdjumov- } \\
\text { Sachs }\end{array}$} & \multirow{2}{*}{$(011)_{\mathrm{bcc}} / /(111)_{\mathrm{fcc}}$} & {$[\overline{1} 11]_{\mathrm{bcc}} / /[\overline{1} 01]_{\mathrm{fcc}}$} & $+2 \%$ \\
\hline & & {$[\overline{1} 1 \overline{1}]_{\mathrm{bcc}} / /[01 \overline{1}]_{\mathrm{fcc}}$} & $+2 \%$ \\
\hline & \multirow{2}{*}{$(11 \overline{1})_{\mathrm{bcc}} / /(10 \overline{1})_{\mathrm{fcc}}$} & {$[\overline{1} 10]_{\mathrm{bcc}} / /[010]_{\mathrm{fcc}}$} & $-11,5 \%$ \\
\hline & & $\left.[\overline{3} 21]_{\mathrm{bcc}} / / \overline{1} 3 \overline{1}\right]_{\mathrm{fcc}}$ & $+10,8 \%$ \\
\hline & \multirow{2}{*}{$(\overline{2} 1 \overline{1})_{\mathrm{bcc}} / /(\overline{1} 2 \overline{1})_{\mathrm{fcc}}$} & {$[131]_{\mathrm{bcc}} / /[210]_{\mathrm{fcc}}$} & $-15.6 \%$ \\
\hline & & {$[\overline{1} 13]_{\mathrm{bcc}} / /[012]_{\mathrm{fcc}}$} & $-15.6 \%$ \\
\hline
\end{tabular}


ble deviation of $11^{\circ}$ from the $\alpha / \gamma$ Bain correspondence [22];

- It is low enough to strongly reduce the free energy barrier to precipitate nucleation;

- It is a posteriori in good agreement with the present results.

The figure 1 is a standard stereographic projection of the ferrite crystal showing small circles of radius $8^{\circ}$ centred on $\langle 110\rangle,\langle 001\rangle,\langle 111\rangle$ and $\langle 211\rangle$ poles.

Depending on whether most poles of the investigated grain-boundary planes were inside or outside the circles, this projection may be used to conclude whether the " $\mathrm{GB} / \alpha / \gamma$ » system is an efficient parameter of the intergranular precipitation.

\section{Results and discussion.}

Depending on the extension of the new phase, it was possible to study simultaneously the three factors of the intergranular precipitation : misorientation, extrinsic dislocations, relative orientation of the grain boundary plane in the two grains or to focus on only one of these factors. In particular, where the precipitates grow, extrinsic dislocations are no longer visible but the morphology (facets or not) and the size of the particles gave valuable information about the role of the third of the named factors.

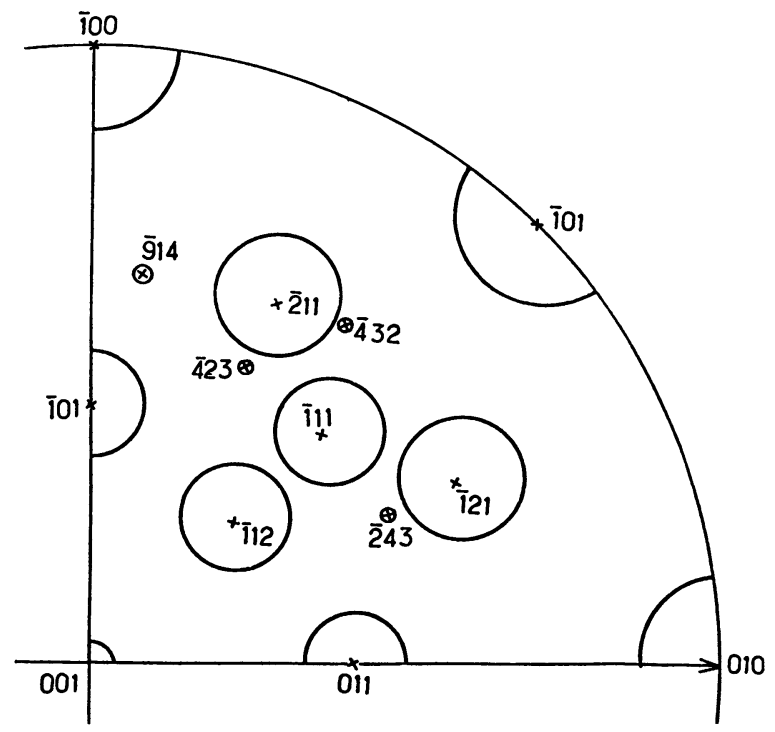

Fig. 1. - Standard stereographic projection of the ferrite showing small circle of radius $8^{\circ}$ centred on $\langle 110\rangle,\langle 001\rangle$, $\langle 111\rangle$ and $\langle 211\rangle$ poles. The grain boundary plane, the pole of which is localized inside these circles, is most probably a favoured one for intergranular precipitation of austenite; this is not the case for a $\{432\}$ or $\{914\}$ plane (see boundary $\mathrm{G} / \mathrm{H}$ in Table II).

4.1 The FaCtors OF THE INTERgRANULAR NUCleaTION. - To perform an investigation of the respective

Table II. - Some examples of the study of the respective influence on the intergranular precipitation of the following factors : - type of the grain boundary « special " or " general »; - extrinsic dislocations; - relative orientation of the grain boundary plane in the two grains.

\begin{tabular}{|c|c|c|c|c|c|}
\hline \multirow{2}{*}{ Boundary } & \multirow{2}{*}{$\begin{array}{c}{\left[\begin{array}{ccc}u & v & w\end{array}\right]} \\
\phi\end{array}$} & \multirow{2}{*}{ Type } & \multicolumn{2}{|c|}{ Boundary plane } & \multirow{2}{*}{$\mathbf{u} \in$} \\
\hline & & & I & II & \\
\hline A/B & $\begin{array}{c}{\left[\begin{array}{lll}9 & 7 & 4\end{array}\right]} \\
42^{\circ}\end{array}$ & G & $\begin{array}{l}8^{\circ} \\
\text { from } \\
(1 \overline{2} 1)_{A}\end{array}$ & $\begin{array}{l}70 \\
\text { from } \\
(1 \overline{1} 0)_{B}\end{array}$ & $(231)_{B}$ \\
\hline$C / D$ & $\begin{array}{c}{\left[\begin{array}{lll}4 & 3 & 2\end{array}\right]} \\
470\end{array}$ & G & $(1 \overline{1} 0)_{C}$ & $(711)_{D}^{*}$ & $(2 \overline{1} 3)_{c}$ \\
\hline$E / F$ & $\begin{array}{c}{\left[\begin{array}{ccc}5 & 4 & 4\end{array}\right]} \\
270\end{array}$ & $\begin{array}{c}\text { C.S.L. } \\
\Sigma=13\end{array}$ & $(211)_{\mathrm{E}}$ & $(\overline{6} 71)_{\mathrm{F}}^{*}$ & $(\overline{3} 21)_{F}$ \\
\hline $\mathbf{G} / \mathbf{H}$ & $\begin{array}{c}{\left[\begin{array}{lll}2 & 1 & 0\end{array}\right]} \\
38^{\circ}\end{array}$ & G & $(\overline{4} 23)_{\mathrm{G}}^{*}$ & $(\overline{9} 1 \overline{4})_{\mathrm{H}}^{*}$ & $\begin{array}{l}(2 \overline{11})_{\mathrm{G}} \\
(2 \overline{11})_{\mathrm{H}}\end{array}$ \\
\hline $\mathrm{I} / \mathrm{J}$ & $\begin{array}{c}{\left[\begin{array}{ccc}1 & 1 & 0\end{array}\right]} \\
50^{\circ}\end{array}$ & $\begin{array}{l}\text { C.S.L. } \\
\Sigma=11\end{array}$ & $(\overline{1} 14)_{1}^{*}$ & $\begin{array}{l}5^{0} \\
\text { from } \\
(\overline{1} 21)_{J}\end{array}$ & $(\overline{3} 12)_{\mathrm{I}}$ \\
\hline
\end{tabular}

$*$ : plane lying more than $8^{\circ}$ away any $\{110\},\{100\},\{111\},\{211\}$ plane. 
influence of the different parameters, including intergranular linear defects, the samples analysed in this chapter were annealed at the lowest possible temperature of $645^{\circ} \mathrm{C}$ to strictly control the phase transformation. 15 grain boundaries containing precipitates were analysed. Table II gives an example of the procedure. Four boundaries were « special ". This relative number was in agreement with the proportion of special boundaries among the random ones without precipitate [19], thus we could not draw conclusions on the dependence of nucleation on the intergranular structure.

The influence of extrinsic dislocations upon nucleation was revealed in two special boundaries $\mathrm{E} / \mathrm{F}$ and $\mathrm{I} / \mathrm{J}$ and three general boundaries $\mathrm{A} / \mathrm{B}, \mathrm{C} / \mathrm{D}$ and $\mathrm{G} / \mathrm{H}$ where either the precipitates were stretched parallel to a dislocation line (Figs. 2 and 3 ) or one of their side lay parallel to this line which is the trace of a possible $\{211\}_{\mathrm{bcc}}$ or $\{321\}_{\mathrm{bcc}}$ glide plane of one grain upon the grain boundary plane (Figs. 4 and 5).
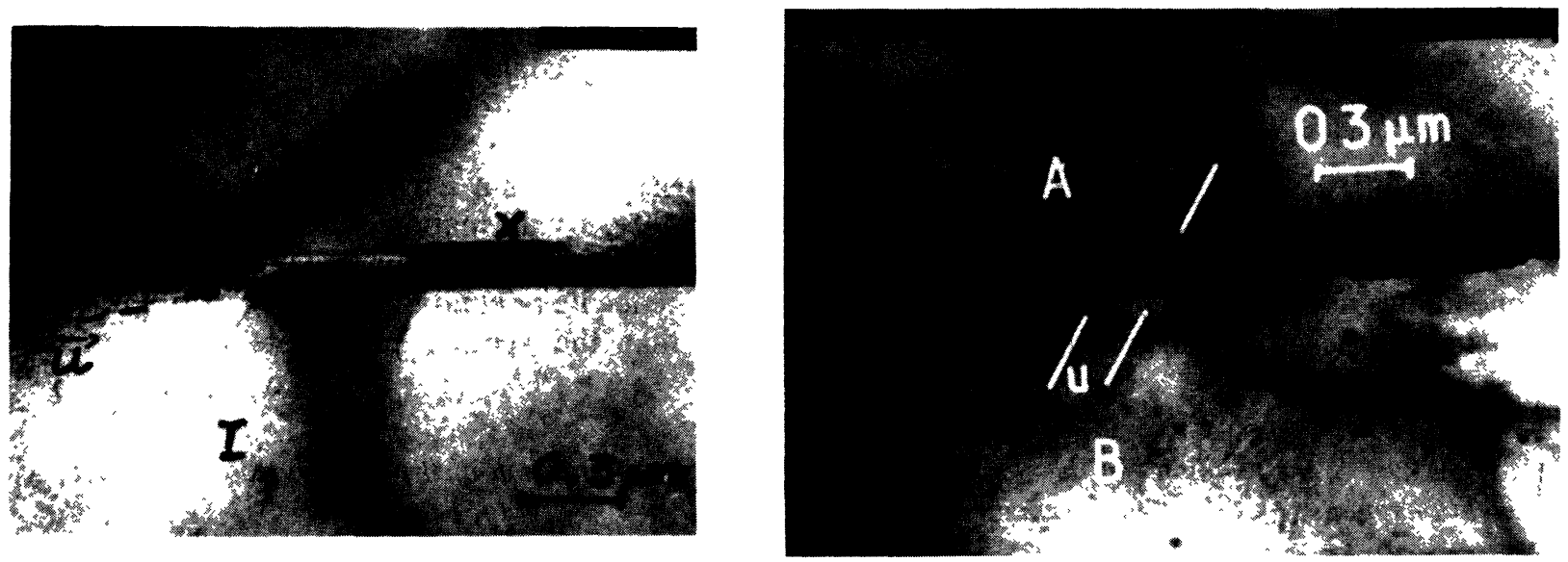

Fig. 2. - Small precipitates along the direction $\mathbf{u}$ which is the trace on the boundary plane $I / J$ of the $(\overline{3} 12)_{1}$ plane. Precipitate $X$ has a straight interface with grain $\mathbf{J}$ almost parallel to the grain boundary plane $(\overline{1} 21)_{J}$.

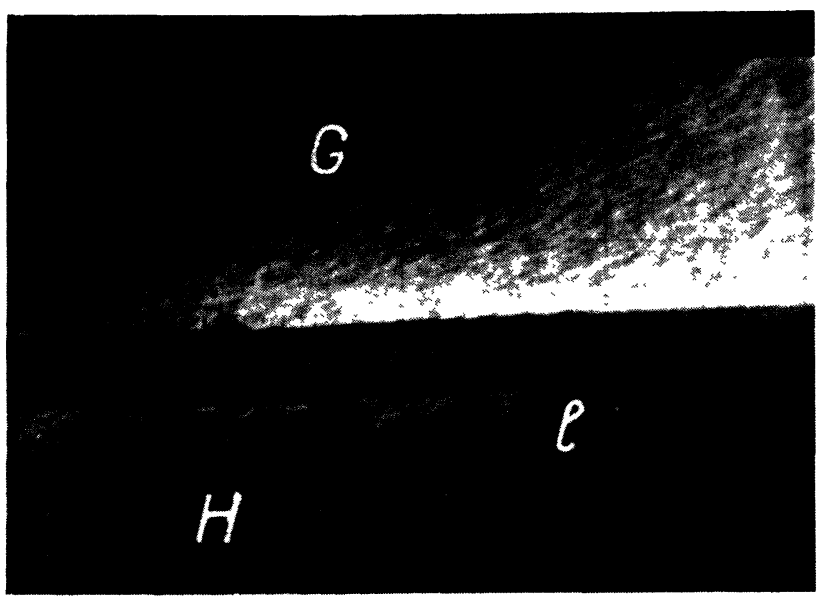

Fig. 3. - Microprecipitates appear parallel to the extrinsic dislocation lines (1) in general boundary $\mathrm{G} / \mathrm{H}$.

Fig. 5. - Many precipitates in the general grain boundary A/B, the sides of which are most often parallel to the trace of a glide plane upon the grain boundary plane $\left(\mathbf{u}=(231)_{\mathbf{B}} \wedge(1 \overline{1} 0)_{\mathbf{B}}\right)$.

Precipitation was also found to occur when grain boundaries do not contain linear defects. In this case, the orientation of the grain boundary plane was always found to lie near a possible habit plane of one grain at least, that is, the $\phi$ angle previously defined was less than $8^{\circ}$.

Otherwise, the density and the growth of the particles seemed to be connected with the orientation of the grain-boundary plane. When this plane lay more than $8^{\circ}$ away from any $\{110\},\{100\},\{211\}$ or $\{111\}$ plane of the two adjoining grains $(\mathrm{G} / \mathrm{H}$ boundary - Fig. 3), the microprecipitates were closely associated to the dislocations lines.

In the other cases $\left(\phi<\phi_{\mathrm{c}}\right.$ in one grain at least) either the precipitates extended along the grainboundary interface or they grew into one or both ferrite grains. In the E/F boundary, the precipitate did 
not develop in grain $\mathrm{E}$ as $(211)_{\mathrm{E}}$ was strictly parallel to the boundary plane and grew into grain $F$ where the value of $\phi$ approached $\phi_{\mathrm{c}}$ (Fig. 4). In the I/J boundary, the precipitate $X$ had a straight interface parallel to the boundary plane (about $\left.(\overline{1} 21)_{\mathrm{J}}\right)$ and extended slightly across the grain I, the grain boundary plane (114) , being far from any low energy interface (Fig. 2). Our first observations seemed to be in agreement with Smith's hypothesis [33] : a low value of $\phi$ permits the formation of an « immobile " coherent interface and thus impedes the development of precipitate, on the contrary a high value of $\phi$ may allow extension.

From these preliminary analyses, it is not possible to draw any conclusions as to the " hierarchy " of the parameters of nucleation suggested by Gronski [17]. On one hand, extrinsic dislocations act as preferential nucleation sites in any boundary, and their presence may be considered as a predominant factor. On the other hand, a favourable orientation of the boundary plane appears necessary to promote nucleation in boundaries without linear defects. Where the two factors occur (as in the case of A/B boundary), the morphology of the precipitates may be explained by two processes :

- either the new phase nucleates on the dislocation lines and grows along the boundary plane which is close a possible low-energy interface in the two grains;

- or the favourable orientation of the boundary plane allows nucleation, then the linear defects act as barriers for the growth of precipitates in the plane.
Thus the nucleation of intergranular precipitation in polycrystals must depend on the thermomechanical history and on the purity of the materials as it depends on the stability of extrinsic dislocations [20].

The crystallographic system constituted by the boundary plane, the matrix grains and the precipitate has an obvious importance on the subsequent growth that needs to be emphasized.

4.2 THE DEPENDENCE OF PRECIPITATION ON THE CRYSTALLOGRAPHIC "GB $/ \alpha / \gamma$ » SYSTEM. - The investigations made on samples which underwent phase transformation either simultaneously to or after recrystallisation led to analogous results. Among them four typical ones are illustrated in table III and a detailed account is given hereafter.

- Two single crystals of austenite hardly expanded in the $\mathrm{a} / \mathrm{b}$ boundary as the annealing temperature in the $(\alpha \overline{+\gamma})$ domain was still low. Crystal $\mathrm{x}$ is located entirely in grain a; crystal y grew preferentially into grain a and it has an interface extremely close the boundary in grain $b$ (Fig. 6). From these observations it is highly likely that precipitates nucleated in grain $\underline{b}$ where they could not extend as their interface was a very low energy one (close $\left.(\overline{110})_{\alpha}\right)$. The occurrence of misfit dislocations in the $\mathrm{x} / \mathrm{a}$ interface suggests an extension in grain a by migration of a semi-coherent interface. The formation of a single crystal precipitate on both sides of a grain boundary implies that the ferrite-ferrite orientation relationships are not random or that the specific precipitate-matrix orientation

Table III. - Some examples of the study of the influence of the orientation of the grain boundary plane upon the nucleation and the growth of intergranular precipitates.

\begin{tabular}{|c|c|c|c|c|c|c|}
\hline \multirow{2}{*}{ Heat-treatments } & \multirow{2}{*}{ Boundary } & \multirow{2}{*}[\begin{array}{lll}{u}&{v}&{w}\end{array}]{} & \multirow{2}{*}{ type } & \multicolumn{2}{|c|}{ Boundary plane } & \multirow{2}{*}{ Observations } \\
\hline & & & & I & II & \\
\hline \multirow{2}{*}{$\begin{array}{l}24 \mathrm{~h} \text { at } \\
655^{\circ} \mathrm{C} \\
\text { (just above } \\
\alpha \rightarrow \alpha+\gamma \text { ) }\end{array}$} & $a / b$ & $\begin{array}{c}{\left[\begin{array}{lll}6 & 3 & 2\end{array}\right]} \\
45^{\circ}\end{array}$ & $\mathbf{G}$ & $\begin{array}{c}7^{\circ} \\
\text { from } \\
(\overline{110})_{a}\end{array}$ & $\begin{array}{l}(\overline{130})_{\mathrm{b}} \\
\text { random }\end{array}$ & $\begin{array}{l}\text { preferential growth } \\
\text { of two precipitates in } \\
\text { grain b (Fig. 6) }\end{array}$ \\
\hline & $\mathrm{c} / \mathrm{d}$ & {$\left[\begin{array}{lll}1 & 1 & 1 \\
44^{\circ}\end{array}\right]$} & C.A.D. & $\begin{array}{c}8^{\circ} \\
\text { from } \\
(211)_{c}\end{array}$ & $\begin{array}{c}(561)_{d} \\
11^{\circ} 5 \text { from } \\
(110)_{d}\end{array}$ & $\begin{array}{l}\text { - growth in grain d } \\
\text { - small extension in } \\
\text { grain d (Fig. 7) }\end{array}$ \\
\hline $\begin{array}{l}24 \mathrm{~h} \text { at } 675^{\circ} \mathrm{C} \text { (in } \\
\text { the middle of } \\
\alpha+\gamma \text { ) }\end{array}$ & $x / y$ & 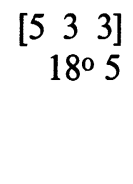 & G & $\begin{array}{c}6^{0} \\
\text { from } \\
(1 \overline{2} 0)_{x}\end{array}$ & $\begin{array}{c}5^{0} \\
\text { from } \\
(0 \overline{11})_{y}\end{array}$ & $\begin{array}{l}\text { growth in grain } \\
\text { straight interface } \\
\text { // to the boundary pla- } \\
\text { ne in y (Fig. 9) }\end{array}$ \\
\hline $\begin{array}{l}24 \mathrm{~h} \text { at } 600^{\circ} \text { in } \alpha \\
\text { region }+15 \mathrm{~min} \text { at } \\
\text { at } 735^{\circ} \text { (in } \alpha+\gamma \\
\text { region) }\end{array}$ & $\mathrm{X} / \mathrm{Y}$ & $\begin{array}{c}{\left[\begin{array}{lll}9 & 1 & 0\end{array}\right]} \\
19^{\circ}\end{array}$ & G & $\begin{array}{l}6^{0} \\
\text { from } \\
(\overline{1} 01)_{x}\end{array}$ & $\begin{array}{c}6^{0} \\
\text { from } \\
(\overline{2} 01)_{Y}\end{array}$ & $\begin{array}{l}\text { - growth in grain } Y \\
\text { interface almost pa- } \\
\text { rallel to the bounda- } \\
\text { ry plane in X } \\
\text { (Fig. 10) }\end{array}$ \\
\hline
\end{tabular}




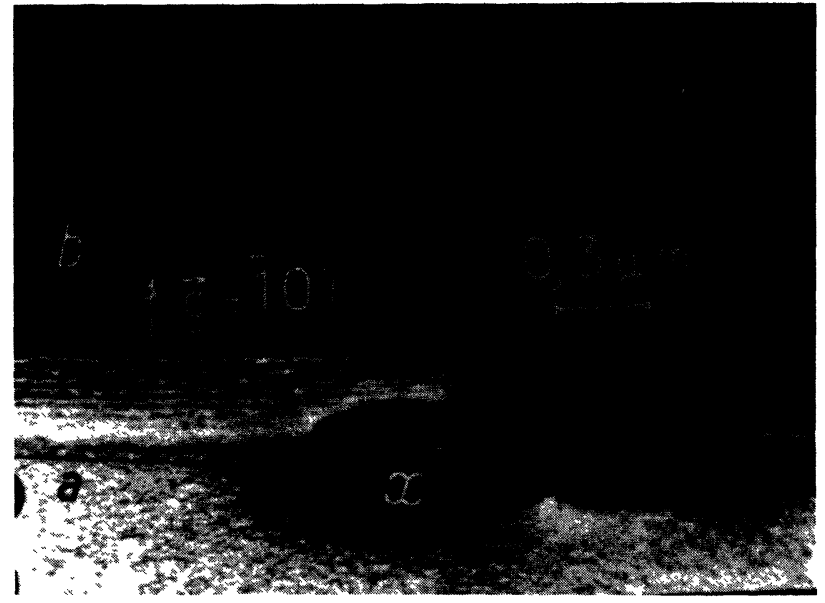

$\mathbf{a}$

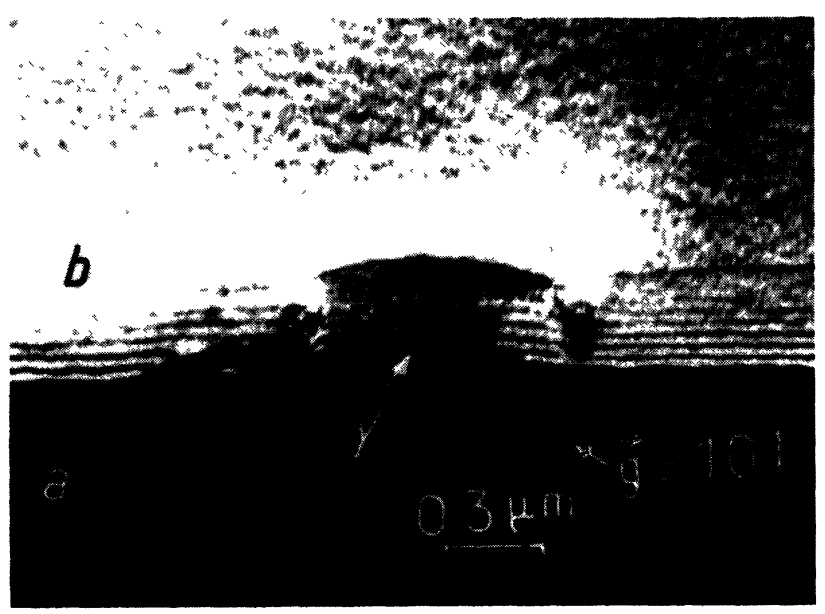

$\mathbf{b}$

Fig. 6. - Dark field images of the boundary $a / b$ showing that the precipitates $x$ is entirely located in grain a and that the precipitate $\underline{y}$ extended a little more in grain $\underline{a}$ (Fig. 6a) than in grain $b$ (Fig. 6b), dislocations suggests that the $\underline{x} / \mathbf{a}$ interface is a semi-coherent one (Fig. 6a).

relationships may be violated. This problem is discussed in the next section.

- An example of precipitation at a triple point is shown on figure 7. Particles 1 to 4 are located at the c/d boundary. The comparison between the TEM observations in bright field (Fig. 7a) and those in dark field (Fig. 7b and c) allows us to understand the growth of these precipitates into the two grains. It is clear from figure $7 \mathrm{~b}$ that the particles 2 and 3 developed in grain c. Although the particle 4 hâs a similar form and a similar orientation as the others, it appears located entirely in grain $\mathrm{d}$. The white border $\mathrm{L}$ along the boundary in grain $\overline{\mathrm{d}}$ (Fig. 7a) present thickness fringes on the dark field image with the diffraction vector $\mathbf{g}=[110]_{\mathrm{d}}$ (Fig. $\left.7 \mathrm{c}\right)$.

In the same condition particles 3 and 4 are visible. These observations suggest the configuration in the thin foil (Fig. 8) : a selective dissolution of grain $\underline{\mathrm{c}}$ occurred during thinning which involved the disappearance of one part of the particle 4. Assuming that $x$ is the projection on the image (Fig. 7a) of the space point X (Fig. 8), it is highly likely that precipitate 4 had a small spacing to the boundary in grain d. By contrast, the extension of the particle 1 (Fig. $7 \bar{a})$ indicates a preferential growth in grain $\bar{c}$ (Fig. 8) that most probably concerns the four precipitates of similar morphology. According to diffraction analysis these four precipitates are single crystals in relation with both matrix grains. Wherever the side of the boundary, the value of $\phi$ does not allow conclusions on nucleation. But the difference in growth may indirectly provide information about the interface energy that seems lower for $(100)_{\alpha} /(111)_{\gamma}$ than for $(211)_{\alpha} /(211)_{\gamma}$ as the precipitate/grain $d$ interfaces were less mobile. This analysis is supported by our theoretical approach of coherency (Table I, Chapter 3); it implies that $\Delta \theta$, which is normally varying with the interface, may be more than $8^{\circ}$ in the special case of the lowest energy interface $\left[(110)_{\alpha} /(111)_{\gamma}\right]$.

Furthermore, each precipitate exhibited a preferential axis of growth approximately parallel to periodic lines in the boundary (Fig. 7d). These lines are the intersections with the boundary plane of (111) planes of the two grains which must be in good matching in a special CAD boundary described by a rotation around [111] [35]; they correspond to a network of intrinsic dislocations of Burgers Vector $\mathbf{b}_{3}=\frac{a}{2}[111]$. By measuring the distance between two lines, the misorientation between $(111)_{c}$ and (111) has been found equal to $0.5^{\circ}$.

This observation suggests that structural dislocations may play a role in intergranular precipitation.

- Although the heat treatments were different, the crystallographic analysis performed on the two following investigated boundaries are similar (cf. Table III). However two features distinguish the precipitates in $\mathrm{x} / \mathrm{y}$ boundary from that in $\mathrm{X} / \mathrm{Y}$ one (Figs. 9 and 10) :

- when the precipitation anneal was performed after recrystallisation $(\mathrm{X} / \mathrm{Y})$ a change of the boundary plane may be observed (Fig. 10);

- in the $\mathrm{x} / \mathrm{y}$ boundary, precipitates constituted by the metastable $\alpha^{\prime}$ phase at room temperature, display $\mathrm{Fe}_{3} \mathrm{C}$ carbides identified by the Convergent Beam Diffraction technic. They most probably appeared by cooling of the austenite phase enriched in carbon (Fig. 9b).

In both cases, the precipitates are more developed than previously and essentially on one side of the boundary. The observation of a straight interface superimposed to the boundary in one grain and that of facets in the other grain imply the occurrence of a good orientation relationship to both grains. Following a procedure already used [22-23] in order to interpret this double orientation relationship, we have illustrated on a stereographic projection of the two crystals 

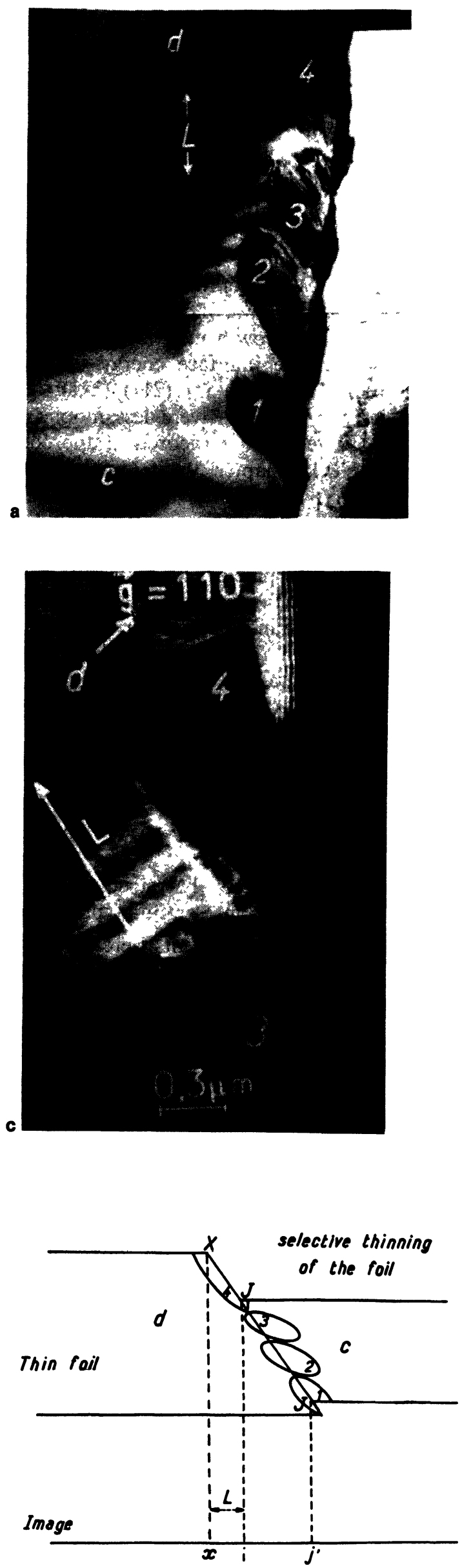
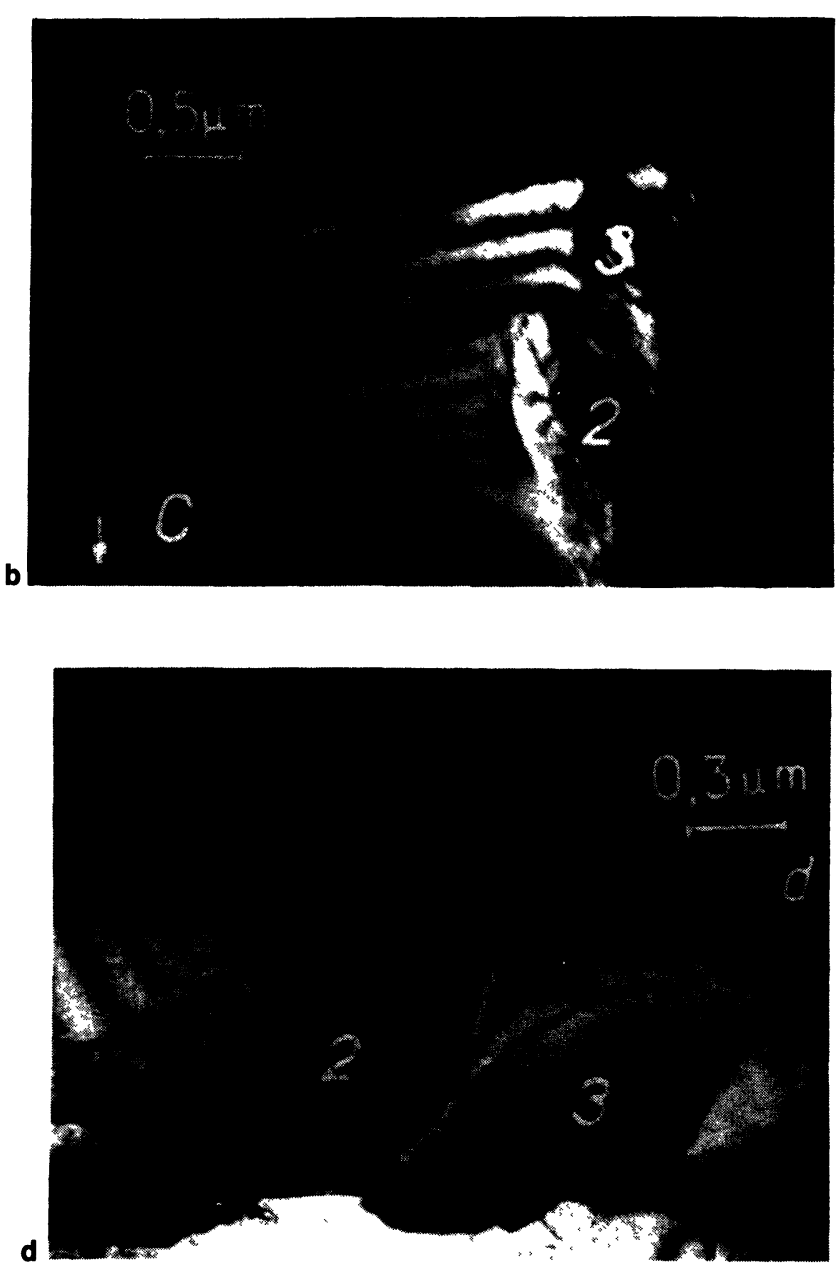

Fig. 7. - a) Bright field image of four precipitates localized in the $\mathrm{c} / \mathrm{d}$ boundary at a triple point.

b) Dark field image with a diffraction vector of grain $\underline{\mathbf{c}}$ showing that particle 4 is not situated in that grain in spite of the same morphology as the others precipitates.

c) On the dark field image obtained with $g=[\overline{1} 10]_{d}$, the particle 4 is now visible and thickness fringes appear in the border $\overline{\mathrm{L}}$ along the boundary plane.

d) Each particle displays an axis parallel to the direction of an intrinsic dislocation network which corresponds to the geometrical description of a [111] C.A.D. grain boundary (see test).

Fig. 8. - Configuration of the precipitates in the thin foil explaining their images in the three previous conditions (Figs. 7a, b, c) (see text). 

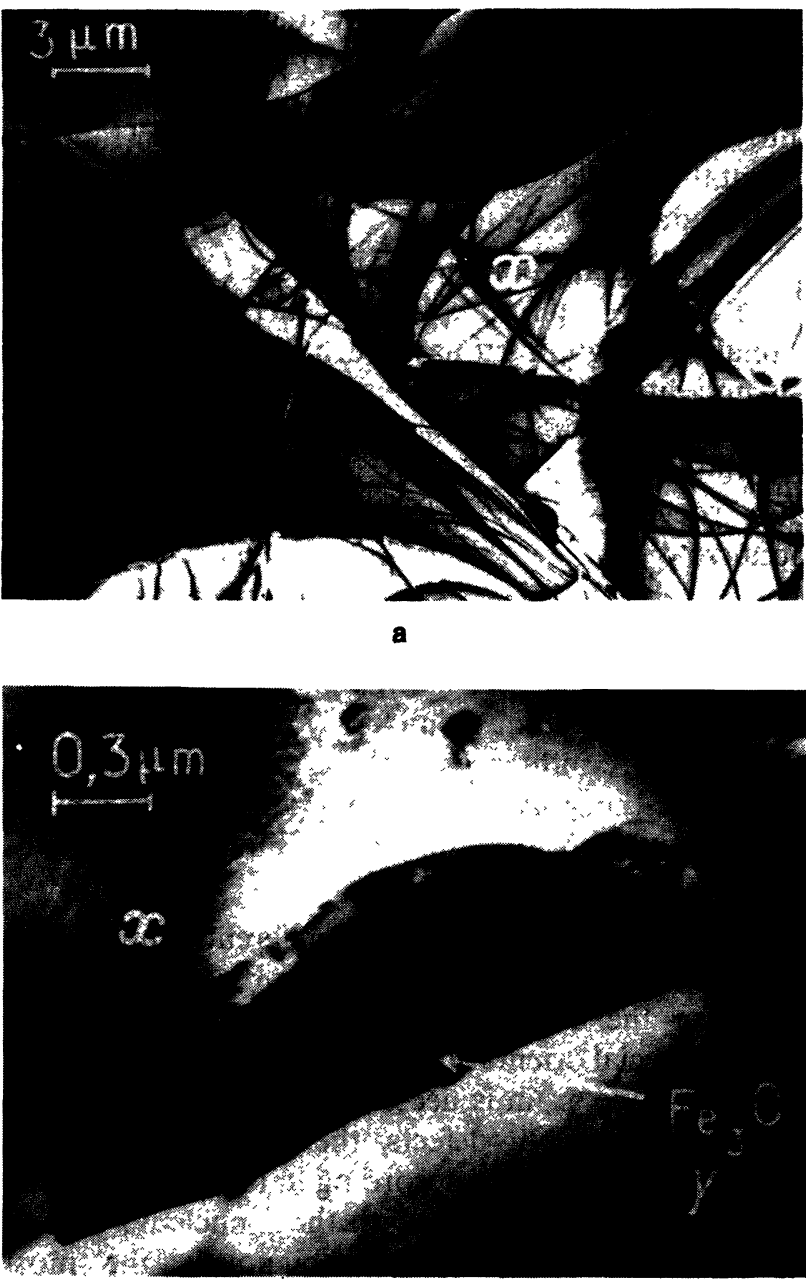

Fig. 9. - a) Three crystals of the new $\alpha^{\prime}$ phase are developed on the same side of the ferrite grain boundary $x / y$.

b) Detail of one of these crystals showing its straight interface parallel to the grain boundary plane in grain $y$, the occurrence of facets in grain $\mathrm{x}$ and the presence of $\mathrm{Fe}_{3} \mathrm{C}$ carbides inside the $\alpha^{\prime}$ phase (see text).

the « Bain orientation regions " corresponding to all the austenite/ferrite orientation relationships within $11^{\circ}$ from the Bain correspondence :

$$
\begin{aligned}
& (100)_{\mathrm{bcc}} / /(100)_{\mathrm{fcc}} \\
& (011)_{\mathrm{bcc}} / /(010)_{\mathrm{fcc}} \\
& (01 \overline{1})_{\mathrm{bcc}} / /(001)_{\mathrm{fcc}} .
\end{aligned}
$$

These regions are represented by small circles of radius $11^{\circ}$ centred on the $\{100\}_{\alpha}$ and $\{110\}_{\gamma}$ poles. Figure 11 shows this projection in the case of the $x / y$ boundary. As the Bain regions of the two crystals partially overlapped, it was possible to localize three $\{100\}_{\gamma}$ poles in the overlapping areas that involve the Bain orientation relationship of a single $\gamma$ crystal to both matrix grains. Then we have verified the possibility for a $\{111\}_{\gamma}$ pole to be close to the grain boundary plane $\mathrm{P}$, that is to lie at less than $8^{\circ}$ from
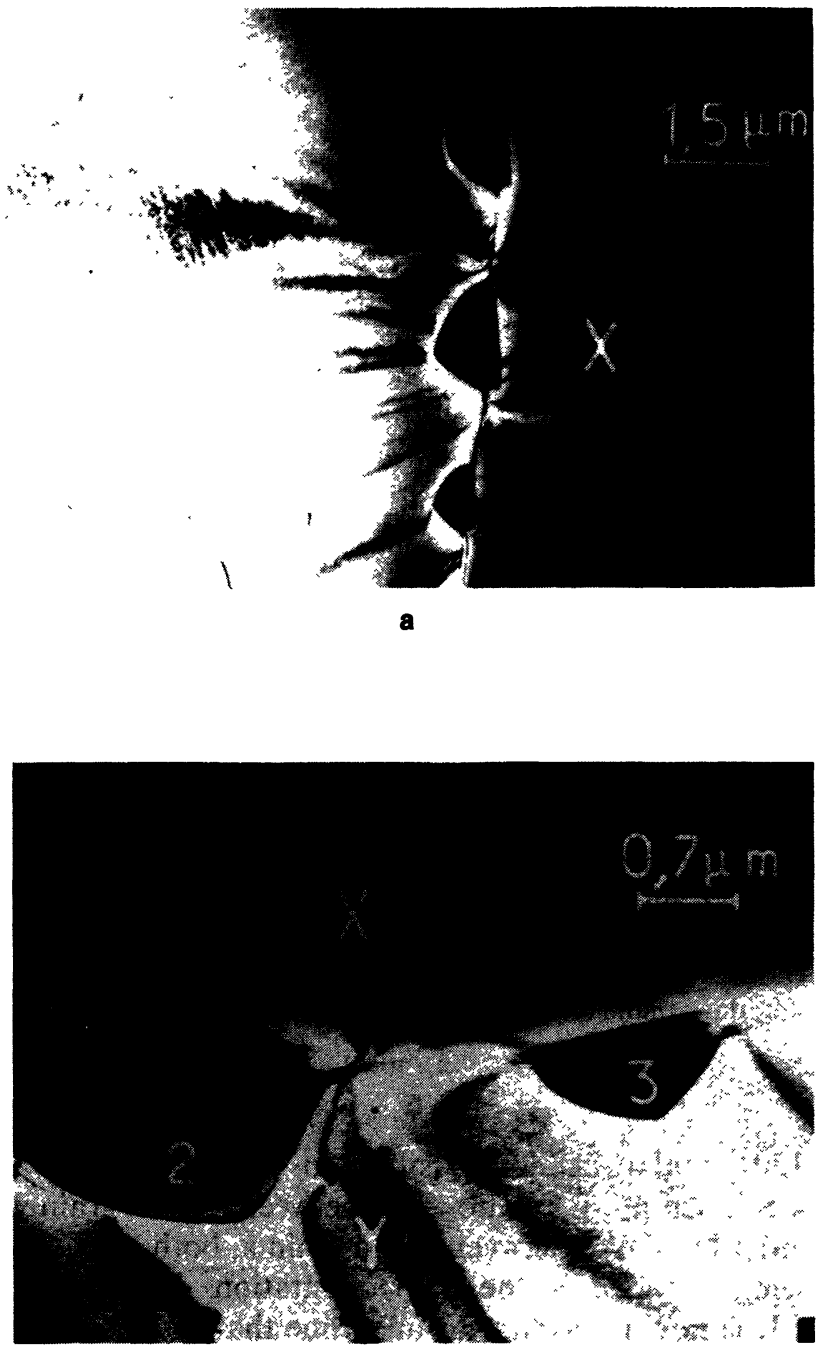

b

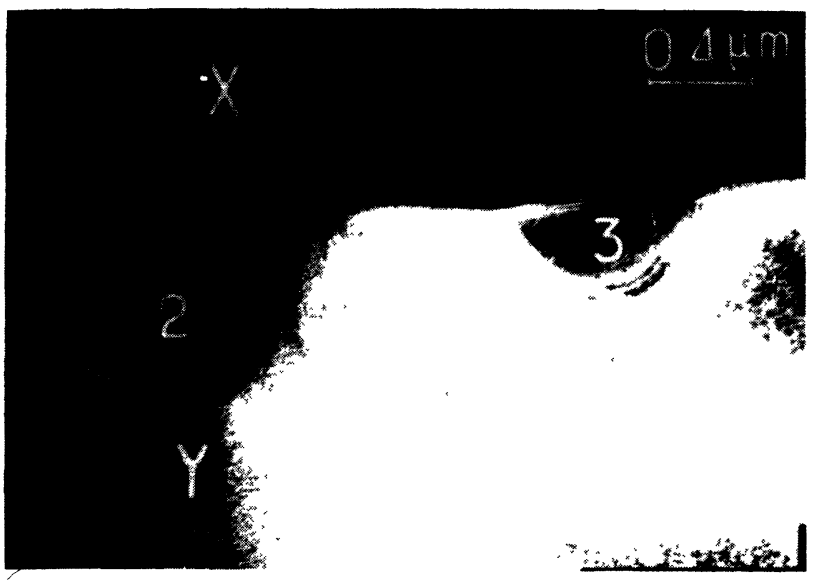

Fig. 10. - a) Three crystals of $\alpha^{\prime}$ phase in the grain $Y$

b) Details of the particles 2 and 3 : straight interfaces with grain $X$, facets with grain $Y$ (Bright Field image).

c) Dark field image with $\mathbf{a}$ diffraction vector $\mathbf{g}_{\mathbf{Y}}$ showing changes of the grain boundary plane induced by the precipitation. 


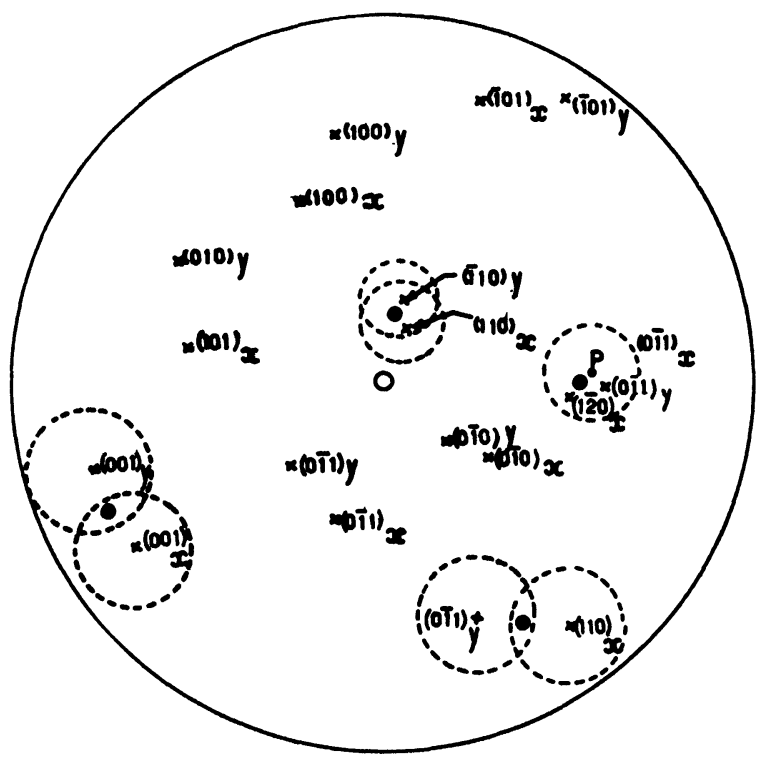

Fig. 11. - Stereographic projection of the $\langle 100\rangle$ and $\langle 110\rangle$ poles of the two ferrite crystals $\mathrm{x}$ and $\mathrm{y}$ showing that their "Bain regions" ( $Q$ ) overlap. A single intergranular austenite crystal $(\oplus$ poles) may develop in good orientation relationship (K S or NW) with both crytals so that a $\{111\} \gamma$-plane may be almost parallel to the grain boundary plane $(0 \overline{1} 1)_{y} / /(1 \overline{2} 0)_{x}$.

$(1 \overline{2} 0)_{\mathrm{x}}$ and $(0 \overline{1} 1)_{\mathrm{y}}$. This situation corresponds to a K-S orientation relationship between $\gamma$ and grain y and a N-W one between $\gamma$ and grain $\mathrm{x}$, both relations being included in the Bain orientation relationship.

It is now important to underline that no misorientation exists between the $\alpha^{\prime}$ phase and the $\alpha$ grain in which it is located. This feature suggests that, on cooling, the reverse transformation $\gamma \rightarrow \alpha^{\prime}$ takes place with the same variants of the orientation relationship as those occuring on heating $\alpha \rightarrow \gamma$. This hypothesis allows the possibility for a single $\gamma$ crystal extended in both matrix grains to divide in two $\alpha^{\prime}$ parts of different orientation across the previous $\alpha / \gamma$ boundary.

This situation has been observed in pure $\mathrm{Fe}-4 \% \mathrm{Ni}$ alloys containing only $50 \times 10^{-6}$ carbon [24]; it may be explained by the important role of the interfaces in the massive transformation $\gamma \rightarrow \alpha^{\prime}$ which starts on different interfaces in one or in the other side of the $\gamma$ precipitates $\left(\gamma / \alpha_{1}\right.$ or $\left.\gamma / \alpha_{2}\right)$.

Taking into account all the investigated boundaries in this second part of the work, the following results may be pointed out :

- intergranular precipitation occurred more often in general boundaries;

- the precipitates nucleated in the grain, where the boundary plane was close to $\{110\}_{\alpha}$. In few cases they grew a little into that grain, more usually they extended along the boundary giving rise to a straight interface superimposed on the boundary plane;

- nucleating in one grain, the precipitates grew into the other one and, in most cases, a non-random orientation relationship existed between the two matrix grains;

- other grain boundary planes as $\{100\},\{111\}$, $\{211\}$ which can form a low $\alpha / \gamma$ energy interface with a relatively high misfit have been found to play a role in nucleation, especially in alloys with lower C contents [34]. In these cases, the possibility of a double favoured orientation of the boundary plane was higher than previously and precipiates extended apart the boundary.

\section{Conclusions.}

The most important results of this study concerning the respective influences of the crystallographic parameters of the grain boundary/grains system on the intergranular precipitation of austenite in ferrite are as follows :

1) Extrinsic dislocations are preferential nucleation sites in any boundary "special " or " general " and whatever the other parameters.

2) A special orientation of the grain boundary plane in at least one grain is necessary for the nucleation in boundaries without defects, the possible nucleation plane may be classified according to the energies of the interfaces they may form with the $\gamma$ nucleus; on this basis $\{110\}_{\alpha}$ plane is unambiguously the most favourable plane as the $\{110\}_{\alpha} / /\{111\}_{\gamma}$ interface has the lowest energy.

3) Growth requires that a good orientation relationship (within the Bain region) exists between the austenite crystal and the ferrite grain in which it develops. Nucleation and growth can occur in opposite grains, if there is a special orientation relationship between the two matrix grains.

4) The extend and the morphology of the precipitate depend on the mobility of the interface :

- a very low-energy interface as (110) $\mathscr{a} /(111)_{\gamma}$ moves essentially by a step process much slower than a medium-energy interface (with higher misfit) which can be formed with $\{100\}_{\alpha},\{111\}_{\alpha}$ or $\{211\}_{\alpha}$. In both cases, the first stage of growth gives rise to straight interfaces,

- an incoherent interface $\left(\phi>\phi_{\mathrm{C}}\right)$ of high energy that migrates by a diffusion process is very mobile.

On the basis of the present results and interpretations, a classification of the various morphologies of the intergranular precipitate has been established in relation to the crystallographic parameters of the "Grain boundary $/ \alpha / \gamma$ » system (Table IV). The authors think that it may probably be generalized to any case of coherent or partially coherent precipitates. 
Table IV. - Relation between the various morphologies of a coherent or partially coherent intergranular precipitate and the crystallographic parameters of the "grain boundary/matrix grains/precipitate " system.

\begin{tabular}{|c|c|c|c|}
\hline Morphology & Nucleation & Growth & $\begin{array}{l}\text { Orientation } \\
\text { relationship between } \\
\text { matrix grains }\end{array}$ \\
\hline $\begin{array}{c}\frac{\text { Microprecipitates }}{\alpha_{1}} \\
\alpha_{2}{ }_{1}^{\prime} /\end{array}$ & $\frac{\text { on extrinsic }}{\text { dislocations }}$ & no & random \\
\hline$\frac{\text { Platelets or disks }}{\alpha_{1}}$ & $\begin{array}{c}\text { on the boundary plane } \\
\mathrm{J} \\
\mathrm{J} / /\left(\alpha_{1} / \gamma\right) \\
\text { low-energy } \\
\mathrm{J} / /\left(\alpha_{1} / \gamma\right) / /\left(\alpha_{2} / \gamma\right) \\
\text { low-energy }\end{array}$ & $\begin{array}{l}\text { along the boundary plane } \\
\text { in grain } \alpha_{1} \\
\text { in both grains }\end{array}$ & $\begin{array}{c}\text { random } \\
------ \\
\text { whatever }\end{array}$ \\
\hline$\frac{\text { Facetted semi- }}{\text { allotriomorph }}$ & $\begin{array}{l}\text { on the boundary plane } \\
\text { - in grain } \alpha_{2} \\
-\mathrm{J} / /\left(\alpha_{2} / \gamma\right) \\
\text { low-energy } \\
-\mathrm{in} \text { grain } \alpha_{1} \\
\mathrm{~J} / / /\left(\alpha_{1} / \gamma\right) \\
\text { medium-energy }\end{array}$ & $\begin{array}{l}\frac{\text { in grain } \alpha_{1}}{\text { (or vice versa) }} \\
--\frac{\mathrm{J} / /\left(\alpha_{1} / \gamma\right)-\ldots}{\text { medium-energy }}\end{array}$ & $\begin{array}{l}\text { Special } \\
------- \\
\text { random }\end{array}$ \\
\hline$\frac{\text { Semi-allotriomorph }}{\alpha_{1}}$ & $\begin{array}{l}\text { on the boundary plane } \\
\text { in grain } \alpha_{2} \\
\mathrm{~J} / /\left(\alpha_{2} / \gamma\right) \\
\text { low-energy }\end{array}$ & $\begin{aligned} & \text { in grain } \alpha_{1} \\
& \mathrm{~J} / /\left(\alpha_{1} / \gamma\right) \\
& \text { high-energy }\end{aligned}$ & Special \\
\hline Facetted allotriomorph & $\begin{array}{l}\text { on the boundary plane } \\
\text { in both grains } \\
\mathrm{J} / /\left(\alpha_{1} / \gamma\right) / /\left(\alpha_{2} / \gamma\right) \\
\text { medium-energy } \\
-------- \\
\text { in grain } \alpha_{11} \\
\mathrm{~J} / /\left(\alpha_{1} / \gamma\right) \\
\text { medium-energy }\end{array}$ & $\begin{array}{l}\frac{\text { limited growth with }}{\text { facetting in both }} \\
\text { grains } \\
\begin{array}{c}\text { in both grain } \\
\mathrm{J} / /\left(\alpha_{2} / \gamma\right) \\
\text { high-energy }\end{array}\end{array}$ & Special \\
\hline $\begin{array}{l}\frac{\text { Equiaxed }}{\text { allotriomorph }} \\
\alpha_{1}\end{array}$ & $\begin{array}{l}\text { one of the two } \\
\text { previous cases }\end{array}$ & $\begin{array}{l}\text { extended growth } \\
\text { in both grains }\end{array}$ & Special \\
\hline
\end{tabular}




\section{References}

[1] Porter, D. A., Easterling, K. E., Phase Transformation in Metals and Alloys (Ed. Ven. Norstrand Reinhold) 1981.

[2] Aaronson, H. I., LeE, J. K., Lectures on the theory of phase transformations (Ed. by H. I. Aaronson) 1975, p. 103.

[3] Lee, J. K., Aaronson, H. I., Acta Met. 23 (1975) I, p. 799 ; II, p. 809.

[4] Le Coze, J., J. Physique Colloq. 36 (1975) C4-263.

[5] Lorimer, G. W., J. Physique Colloq. 36 (1975) C4-233.

[6] Vaughan, D., Acta Met. 16 (1968) 563.

[7] Unwin, P. N. J., Nicholson, R. B., Acta Met. 17 (1969) 1379.

[8] Vaughan, D., Acta Met. 18 (1970) 183.

[9] Adamson, J. P., Martin, J. W., Acta Met. 19 (1971) 1015.

[10] Pumphrey, P. H., Scripta Met. 7 (1973) 1043.

[11] Clough, S. P., Lee, J. K., Bradley, J. R., Carlson, J. A., Lange, W. F., Michaels, K. F., Seaton, C., Aaronson, H. I., Russel, K. C., Scripta Met. 8 (1974) 101.

[12] Simon, J. P., Guyot, P., J. Mat. Sci. 10 (1975) 1947.

[13] Butler, E. P., Swann, P. R., Acta Met. 24 (1976) 343.

[14] Jones, A. R., Howell, P. R., Ralph, B., J. Mat. Sci. 11 (1976) (1) 1593 ; (2) 1600.

[15] Henry, G., Maitrepierre, Ph., Michaut, B., Thomas, B., J. Physique Colloq. 36 (1975) C4-245.

[16] VARIN, R. A., J. Mat. Sci. 14 (1978) 811.
[17] Gronsky, R., Furrer, P., Met. Trans. 12A (1981) 121.

[18] Khalfallah, O., Priester, L., Revue Phys. Appl. 16 (1981) 153.

[19] Lartigue, S., Khalfallah, O., Priester, L., Revue Phys. Appl. 17 (1982) 649.

[20] Lartigue, S., Priester, L., Acta Met. 31 (1983) 1809.

[21] PRIESTER, L., J. Microsc. Spectrosc. Electron. 8 (1983) 211.

[22] Ryder, P. L., Pitsch, W., Mehl, R. F., Acta Met. 15 (1967) 1431.

[23] King, A. D., Bell, T., Met. Trans. 6A (1975) 1419.

[24] Pumphrey, P. H., Gleiter, H., Philos. Mag. 30 (1974) 593.

[25] VARIN, R. A., TANGRI, K., Met. Trans. 12A (1981) 1859.

[26] Grimmer, H., Acta Cryst. A 30 (1974) 685.

[27] Brandon, D. G., Acta Met. 14 (1966) 1479.

[28] Khalfallah, O., Thesis Orsay (1980).

[29] Warrington, D. H., Boon, M., Acta Met. 23 (1975) 599.

[30] Ecob, R. C., RalPh, B., Acta Met. 29 (1981) 1037.

[31] Vaughan, D., Silcock, J. M., Phys. Status Solidi 20 (1967) 725.

[32] Hall, M. G., Aaronson, H. I., Kinsma, K. R., Surface Sci. 31 (1972) 257.

[33] Smith, C. S., Trans. Am. Soc. Metals 45 (1953) 533.

[34] BenfeTima, N., Thesis Orsay (1983).

[35] Priester, L., Revue Phys. Appl. 15 (1980) 789. 